\title{
Should Capital Flow from Rich to Poor Countries?
}

\author{
Alexander Monge-Naranjo, Luan M. Sánchez, Raül Santaeulàlia-Llopis, and Faisal Sohail
}

Are human and physical capital stocks allocated efficiently across countries? To answer this question, we need to differentiate misallocation from factor intensity differences. We use newly available estimates on factor shares from Monge-Naranjo, Santaeulàlia-Llopis, and Sánchez (2019) to correctly measure the factor shares of physical and human capital for a large number of countries and periods. We find that the global efficiency losses of the misallocation of human capital are much more substantial than those of physical capital, amounting to 40 percent of the world's output. Moreover, contrary to the findings of Monge-Naranjo, Santaeulàlia-Llopis, and Sánchez (2019) for physical capital, the global misallocation of human capital does not seem to be subsiding. We argue that the proper measure of global misallocation requires considering the potential gains of reallocating both physical and human capital. In this case, the implied efficiency loses from misallocation are up to 60 percent of global output. Attaining those gains, contrary to the prominent Lucas paradox (Lucas, 1990), would often require physical capital to flow from poor to rich countries. (JEL O11, O16, O41)

Federal Reserve Bank of St. Louis Review, Fourth Quarter 2019, 101(4), pp. 277-95. https://doi.org/10.20955/r.101.277-95

\section{INTRODUCTION}

The large dispersion in real wages across countries suggests a potentially huge global misallocation of human capital. Thus, reallocating human capital could substantially increase global output and drastically change the world income distribution. To be sure, reallocating humans across countries is a much more complex endeavor than reallocating physical capital. Migrant workers, and not machines, leave behind friends, families, and other attachments

\footnotetext{
Alexander Monge-Naranjo is an economist and research officer at Federal Reserve Bank of St. Louis and a visiting associate professor at Washington University in St. Louis. Juan M. Sánchez is an economist and assistant vice president at the Federal Reserve Bank of St. Louis and an adjunct lecturer at Washington University in St. Louis. Raül Santaeulàlia-Llopis is a research fellow at Markets, Organizations and Votes in Economics (MOVE), an associate professor of economics at the Autonomous University of Barcelona, and an affiliated research professor at the Barcelona Graduate School of Economics. Faisal Sohail is an assistant professor of economics at the University of Melbourne and was a technical research associate at the Federal Reserve Bank of St. Louis. Raül Santaeulàlia-Llopis thanks the European Research Council (ERC Advanced Grant GA324048 Asset Prices and Macro Policy when Agents Learn [APMPAL]) and the Spanish Ministry of Economy and Competitiveness through the Severo Ochoa Programme for Centers of Excellence in R\&D (SEV-2015-0563) for financial support. The authors thank Oksana Leukhina for comments and suggestions and Juan Vizcaino and Qiuhan Sun for research assistance.

(0) 2019, Federal Reserve Bank of St. Louis. The views expressed in this article are those of the author(s) and do not necessarily reflect the views of the Federal Reserve System, the Board of Governors, or the regional Federal Reserve Banks. Articles may be reprinted, reproduced, published, distributed, displayed, and transmitted in their entirety if copyright notice, author name(s), and full citation are included. Abstracts, synopses, and other derivative works may be made only with prior written permission of the Federal Reserve Bank of St. Louis.
} 


\section{Monge-Naranjo, Sánchez, Santaeulàlia-Llopis, Sohail}

and may face cultural and anti-immigrant resistance. Moreover, the impact-real or perceivedof foreign workers on the local population has been used as a political banner that has no counterpart with the impact of capital inflows. Yet, despite all those frictions and barriers, workers and their human capital have been continuously reallocated across countries, oftentimes in great measure. As of today, in the United States and in many other countries, such a reallocation is evident not only in high-human-capital-intensive institutions, such as universities, hospitals, and research institutions, but also much more generally in stores, restaurants, and farms, all of which often agglomerate workers from all over the world.

In this article, we assess the potential global efficiency gains and distributional impacts of reallocating human capital across countries. To this end, we face a number of challenges. First, we need to take a stand on which factors are fixed in each country and which factors can be reallocated-if any-including human capital. Second, we need to control for factor intensity differences across countries to avoid confusing them with distortions. Third, we need to measure or infer the marginal valuation of human capital across countries and incorporate some of the distributional constraints that countries may impose for the entry of workers from abroad. We use the recent work by Monge-Naranjo, Santaeulàlia-Llopis, and Sánchez (2019) that provides exactly the data required to address these three issues for a sample of 76 countries and for the years 1970 to 2005. First, aside from pure total factor productivity (TFP), natural resources are ultimately the only fixed inputs of production in each country. Using the measures in Monge-Naranjo, Santaeulàlia-Llopis, and Sánchez (2019), we assess the curvature of the production function of the different countries with respect to all the mobile factors, that is, human and physical capital, and evaluate the gains of reallocating human capital only or human and physical capital simultaneously. Second, we use the measures in Monge-Naranjo, Santaeulàlia-Llopis, and Sánchez (2019) to control factor intensity differences across countries, which they show are not sensitive to policy distortions. Third, we circumvent the lack of direct and reliable measurements of the relative value of human capital across countries and periods, using the model to generate two extreme and opposite bounds for the observed costs of labor across countries.

Our basic efficiency benchmark consists of equating the marginal returns to human capital across countries. Doing so points to large misallocation of human capital during the sample period, in the range of 40 to 50 percent of global output, with an upward trend over time. Our findings resemble those in Klein and Ventura (2009) and Kennan (2013), using different models, countries, and data. This basic benchmark abstracts from the barriers to reallocating human capital (workers) across countries, which can be very stringent. Some of the barriers are natural, such as the emotional cost of reallocating human beings across countries with different languages, cultures, and values. But other barriers are the result of policies and legislation, mainly in the more developed countries. Such barriers are surely motivated to prevent a reduction in the wages of some of the domestic workers. In fact, the large implied global output gains from the basic benchmark come at the cost of drastic reductions in the wage rate (per unit of human capital) in developed countries.

To appraise the potential gains in global output without the negative impact on the domestic workers of developed countries, we construct policy counterfactuals that are constrained 
so that the real wages of workers must be kept constant (at the implied levels from the data). By design, if workers were the only factor that could be reallocated across countries, no reallocation would take place and global gains would be zero. However, if both human and physical capital could be reallocated, even under such a conservative exercise, the global gains would be substantially higher than reallocating physical capital alone, around 8 percent to 9 percent of global output in the 1970s and up to 6 percent by the 2000s.. Interestingly, the reallocation is largely from the richer and poorer countries (first and fourth income quartiles) toward the middle ones (second and third income quartiles.)

Overall, a proper assessment of global misallocation considers both human and physical capital. The complementarity between these two factors plays a role, as they must be directed toward the countries with higher fixed productivity, either because of TFP or natural resources. Observed allocations deviate from such an alignment. More interestingly, if human and physical capital can be reallocated jointly to equalize their marginal returns across countries, the direction of the physical capital flows can be reverted relative to the case when physical capital is the only mobile factor. In fact, the premise that capital should flow from rich to poor countries is unwarranted: When both factors are reallocated, capital and labor would flow from some of the poor and middle-income countries toward some of the richer countries. This simple yet often ignored point could be one of the keys to understanding the consequences of alternative integration schemes with or without labor mobility for countries and regions with different productivities and fixed endowments (e.g., the United States and Puerto Rico and the European Union on one side, with NAFTA on the other).

The article is organized as follows. Section 2 describes the data used. Section 3 presents our organizing model framework. Section 4 describes the behavior of the estimated marginal product of human capital. Section 5 presents the main results in terms of misallocation of human capital. Section 6 studies the effect of migration flows on the changes in misallocation over time. The conclusion follows.

\section{DATA}

In this section, we describe the available data, the countries for which we have consistent reliable data, and the method used to compute input's share of output.

\subsection{Countries}

We use Monge-Naranjo, Santaeulàlia-Llopis, and Sánchez's (2019) estimates of the factor shares for natural resources, together with data from Penn World Table (PWT) 8.0 for all other variables, that is, output, labor shares, international prices of consumption, and output, and estimates for physical and human capital. ${ }^{2}$ We have consistent data from 1970 to 2005 for the following 79 countries:

- Africa: Burkina Faso, Côte d'Ivoire, Cameroon, Kenya, Morocco, Mozambique, Niger, Nigeria, Senegal, Tunisia, Tanzania, South Africa, and Zimbabwe

- Asia: Bahrain, China, Hong Kong, Indonesia, India, Iran, Israel, Japan, Jordan, the 
Republic of Korea, Kuwait, Sri Lanka, Malaysia, Oman, the Philippines, Qatar, Saudi Arabia, Singapore, Thailand, Turkey, and Taiwan

- Europe: Austria, Belgium, Bulgaria, Switzerland, Cyprus, Germany, Denmark, Spain, Finland, France, the United Kingdom, Greece, Hungary, Ireland, Iceland, Italy, Luxembourg, Malta, the Netherlands, Norway, Poland, Portugal, and Sweden

- The Americas: Argentina, Barbados, Bolivia, Brazil, Canada, Chile, Colombia, Ecuador, Costa Rica, the Dominican Republic, Guatemala, Honduras, Jamaica, Mexico, Panama, Peru, Paraguay, Trinidad \& Tobago, the United States, and Uruguay

- Oceania: Australia and New Zealand

We exclude Burkina Faso, Nigeria, and Oman from our reallocation exercises because these countries do not have data on human capital. This implies a total of 76 countries for our benchmark sample.

In Section 5.2, we expand our analysis to countries for which we can retrieve information on rents of natural resources, factor shares, physical capital, human capital, and output for the year 2005. The improvement on data collection and sources over time and the presence of new countries since the early 1990s (e.g., from Eastern Europe), implies more countries for which the required data are available. This new set of countries includes Armenia, Benin, Botswana, the Central African Republic, Croatia, the Czech Republic, Estonia, Fiji, Gabon, Kazakhstan, Kyrgyzstan, Latvia, Lesotho, Lithuania, Macao, Mauritania, Mauritius, Moldova, Mongolia, Namibia, Romania, Russia, Rwanda, Serbia, Sierra Leone, the Slovak Republic, Slovenia, Swaziland, Tajikistan, Togo, and Ukraine. This yields a total sample of 107 countries for the year 2005 .

\subsection{Input's Share of Output}

We now explain how we incorporate the Monge-Naranjo, Santaeulàlia-Llopis, and Sánchez (2019) estimates of the factor shares for natural resources, $\phi_{j, t}^{R}$, for the computation of the output shares for capital and labor.

We denote the labor share of output by $\theta_{j, t}$. In this article, we use the PWT variable labsh. This measure of the labor share aims to correct for the part of ambiguous income, mainly proprietors' income (i.e., the self-employed), that needs to be attributed to labor income in order to avoid underestimating the contribution of labor to output. This is a particularly relevant issue in countries in which a significant amount of labor is allocated to family-owned farms and other various forms of self-employment. $\underline{3}$

For the output share of physical capital, denoted here by $\phi_{j, t}^{K}$, the standard practice is to equate it to 1 minus the labor share. All nonlabor income must be capital income, an assumption driven by a constant-returns-to-scale production function with only physical and human capital as factors. Instead, as proposed by Caselli and Feyrer (2007), correctly accounting for the income shares of natural capital factors, the physical capital share should be calculated as

$$
\phi_{j, t}^{K}=1-\theta_{j, t}-\phi_{j, t}^{R} .
$$


Thus, we are able to make this adjustment using data on the income shares of natural capital, $\phi_{j, t}^{R}$, from Monge-Naranjo, Santaeulàlia-Llopis, and Sánchez (2019). Note that the output share of natural resources is important for our computations because it determines the returns to scale of mobile factors-human and physical capital-in each of the countries.

\section{THE MODEL}

In this section, we set out our baseline model and derive the benchmarks used to evaluate the degrees of misallocation of mobile factors across countries.

\subsection{The Baseline Environment}

Consider a world economy, populated by an arbitrary number $J$ of countries, indexed by $j=1,2, \ldots, J$. Given our data, we index the (yearly) time periods by $t=1970,1971, \ldots .2005$. Our baseline model assumes a single tradable good, which can be consumed or invested across all countries. In each country, output is produced using the service flows of the country's stocks of physical capital, $K_{j, t}$; natural resources (land and other natural resources), $T_{j, t}$; and human capital-augmented labor, $H_{j, t}=h_{j, t} L_{j, t}$, where $L_{j, t}$ indicates the number of workers in country $j$ in period $t$ and $h_{j, t}$ their average skills or human capital. Production in the country is also a function of the country's overall TFP, $A_{j, t}$.

Our baseline model stems from the standard one-sector growth model, assuming that production of the good in country $j$ at time $t$ is Cobb-Douglas. Specifically, we consider a production function of $Y_{j, t}$ in the form

$$
Y_{j, t}=A_{j, t}\left(K_{j, t}^{\gamma_{j, t}} T_{j, t}^{1-\gamma_{j, t}}\right)^{1-\theta_{j, t}}\left(H_{j, t}\right)^{\theta_{j, t}}
$$

where $0<\theta_{j, t}<1$ is the labor share of output. The non-labor share of output, $1-\theta_{j, t}$, is divided between a share $\gamma_{j, t}\left(1-\theta_{j, t}\right)$ for produced capital, $K_{j, t}$, and a share $\left(1-\gamma_{j, t}\right)\left(1-\theta_{j, t}\right)$ for natural resources. This specification extends the standard model in two dimensions. First, it introduces non-produced capital (natural resources) $T_{j, t}$. Second, it allows for country-time variation in the factor shares as documented in the previous section.

In our framework, the marginal product of one unit of human capital in terms of the quantity of goods $\left(\mathrm{QMPH}_{\mathrm{j}, \mathrm{t}}\right)$ is simply given by

$$
\mathrm{QMPH}_{j, t}=\theta_{j, t} \frac{Y_{j, t}}{H_{j, t}} .
$$

Similarly, the marginal product of one unit of physical capital in terms of the quantity of goods $\left(Q M P K_{j, t}\right)$ is given by

$$
\mathrm{QMPK}_{j, t}=\phi_{j, t} \frac{Y_{j, t}}{K_{j, t}}=\gamma_{j, t}\left(1-\theta_{j, t}\right) \frac{Y_{j, t}}{K_{j, t}} .
$$




\subsection{Efficient Allocations}

We focus on the efficiency of the allocation of factors across countries, treating the global supply of human and physical capital as predetermined in any period. Thus, we abstract from the impact of misallocation on the incentives to accumulate those factors. Instead, we explore the potential gains, in every period, from reallocating human capital across countries. For concreteness, we assume that all output is globally mobile. For brevity, we bundle the fixed factors in each country, TFP and natural resources, in the term $Z_{j, t} \equiv A_{j, t} T_{j, t}^{\left(1-\gamma_{j, t}\right)\left(1-\theta_{j, t}\right)}$.

3.2.1 Baseline. The optimal global allocation is defined by the maximization of global output

$$
Y_{W, t}^{K^{*}, H^{*}}=\max _{\left\{K_{j, t}, H_{j, t}\right\}} \sum_{j=1}^{J} Z_{j, t}\left(K_{j, t}\right)^{\gamma_{j, t}\left(1-\theta_{j, t}\right)}\left(H_{j, t}\right)^{\theta_{j, t}}
$$

subject to

$$
\sum_{j=1}^{J} H_{j, t} \leq H_{W, t} \text { and } \sum_{j=1}^{J} K_{j, t} \leq K_{W, t},
$$

where $H_{W, t} \equiv \sum_{j=1}^{J} H_{j, t}^{O}$ and $K_{W, t} \equiv \sum_{j=1}^{J} K_{j, t}^{O}$ for all $t$ and $H_{j, t}^{O}$ and $K_{j, t}^{O}$ are the observed levels of human and physical capital, respectively. In addition to equalizing the $Q M P K_{j, t}$ of all countries to a common world price, $r_{t}^{K}$, efficiency requires that all $Q M P H_{j, t}$ be equalized to a common price

$$
r_{t}^{H}=\theta_{j, t} Z_{j, t}\left(K_{j, t}\right)^{\gamma_{j, t}\left(1-\theta_{j, t}\right)}\left(H_{j, t}\right)^{\theta_{j, t}-1} .
$$

Thus, the world supply levels $K_{W, t}$ and $H_{W, t}$ and the productivities and endowments of natural resources $Z_{j, t}$ of all countries pin down the equilibrium $r_{t}^{K}$ and $r_{t}^{H}$. These prices and the factor shares determine the factor intensity of each country:

$$
\frac{K_{j, t}}{H_{j, t}}=\frac{\gamma_{j, t}\left(1-\theta_{j, t}\right)}{\theta_{j, t}} \frac{r_{t}^{H}}{r_{t}^{K}}
$$

The efficient allocation implies that human and physical capital are allocated across countries to complement their TFP and natural resources as allowed by their country-specific returns to scale of mobile factors. There is no closed-form solution except for the case of common (time-varying) factors shares, but the numerical optimization is trivial.

We will also present results for reallocating only human capital. In that case, the allocation of physical capital is taken as given, in the same way that the allocation of natural resources is taken as given in the problem presented above.

3.2.2 Value Benchmark. The previous benchmark presumes that workers are indifferent as to where to work and cross-country differences in output per worker are sustained by policy barriers to worker migration. The global misallocation measure derived from the corresponding counterfactual assesses the global costs of those policy barriers. 
The completely opposite view is that instead of policy barriers, wage differences are sustained by compensating differences; i.e., wage differences are sustained by workers demanding different wages to live in different places. $\underline{4}$ Alternatively, we can consider political constraints that prevent as unfeasible any reallocation that lowers the real wages of workers. In any event, to circumvent these concerns, we now consider the simple exercise in which the reallocation of workers and capital is constrained to keep constant the real wages of workers in all countries in terms of consumption goods.

This exercise requires data on wages (per unit of human capital), the price of consumption, and the price of output, to construct the values of $w_{j, t}^{h} P_{j, t}^{C} / P_{j, t}^{Y}$, real wages in terms of output, for each country in each period. The PWT has measures for the price of consumption and of output but does not contain direct measurements of wages per unit of human capital in terms of output, $w_{j, t}^{h}$. Thus, we use our model and infer these wages as $w_{j, t}=\theta_{j, t} Y_{j, t} / H_{j, t}=Q M P H_{j, t}$. We now explore the misallocation of factors given the constraint that any reallocation must keep the wages of workers in each country at this level. Notice also that if only workers, but no physical capital, are allowed to move, the reallocation would be minimal, due only to the small variation in the data for the relative price $P_{j, t}^{C} / P_{j, t}^{Y}$. Notice also that by fixing the real wages of all countries at a point in time, this counterfactual is consistent with any decomposition of those wages arising from compensating differentials or barriers to the mobility of workers.

For this efficiency benchmark, we keep the assumption that output is completely mobile across countries. $\underline{5}$ Then, the maximization is the same, but the resource constraints are different. First, the global amount of goods paid for human capital services in each period is equal to the one inferred in the data:

$$
\sum_{j=1}^{J} \frac{P_{j, t}^{C}}{P_{j, t}^{Y}} w_{j, t}^{h} H_{j, t} \leq H_{W, t}^{N},
$$

where $H_{W, t}^{N} \equiv \sum_{j=1}^{J} \frac{P_{j, t}^{C} w_{j, t}^{h}}{P_{j, t}^{Y}} H_{j, t}^{O}$ and $H_{j, t}^{O}$ is the observed data value for country $j$ in period $t$. Similarly, we impose the restriction

$$
\sum_{j=1}^{J} \frac{P_{j, t}^{K}}{P_{j, t}^{Y}} K_{j, t} \leq K_{W, t}^{N} .
$$

Finally, as mentioned above, this maximization is also subject to providing the same amount of consumption goods to workers as inferred from the data, before the reallocation.

There is an intuitive interpretation for this exercise. Imagine a firm owner who is able to reallocate resources across countries, and the firm is small enough that it takes prices as given. In terms of wages, imagine this owner is limited by country-specific regulations (unions, minimum wages, and so on) to pay the period- $t$ wage in country $i$ for any worker that the owner reallocates to country $i$ in period $t$. The owner is given the task of reallocating workers across countries to maximize real output subject to keeping the company's payroll constant. Since we measure wages by $Q M P H$ (disregarding $P_{j, t}^{C} / P_{j, t}^{Y}$ differences), the firm's owner has no incentives to reallocate workers if capital cannot be reallocated. In this sense, this exercise provides 
a lower bound for the global gains of human capital reallocation. Once capital can also be reallocated, there are potential gains of reallocating workers, even subject to the constraint of keeping wages constant in each country.

The optimality conditions require the equalization across countries of the price-corrected marginal product of physical and human capital; that is,

$$
R_{t}^{K}=\frac{P_{j, t}^{Y}}{P_{j, t}^{K}} \gamma_{j, t}\left(1-\theta_{j, t}\right) A_{j, t} T_{j, t}^{\left(1-\gamma_{j, t}\right)\left(1-\theta_{j, t}\right)}\left(K_{j, t}\right)^{\gamma_{j, t}\left(1-\theta_{j, t}\right)-1}\left(H_{j, t}\right)^{\theta_{j, t}}
$$

for physical capital and

$$
R_{t}^{H}=\frac{P_{j, t}^{Y}}{P_{j, t}^{C} w_{j, t}^{h}} \theta_{j, t} A_{j, t} T_{j, t}^{\left(1-\gamma_{j, t}\right)\left(1-\theta_{j, t}\right)}\left(K_{j, t}\right)^{\gamma_{j, t}\left(1-\theta_{j, t}\right)}\left(H_{j, t}\right)^{\theta_{j, t}-1}
$$

for human capital. Note that, given the world's returns $R_{t}$ and $R_{t}^{H}$, the physical-to-human capital ratio in country $j$ should be

$$
\frac{K_{j, t}}{H_{j, t}}=\frac{\gamma_{j, t}\left(1-\theta_{j, t}\right)}{\theta_{j, t}} \frac{P_{j, t}^{C} w_{j, t}^{h}}{P_{j, t}^{K}} \frac{R_{t}^{H}}{R_{t}^{K}} .
$$

Thus, in the efficient allocation, physical capital intensity relative to human capital intensity varies across countries according to their (i) factor shares in production, (ii) relative prices of consumption and capital goods, and (iii) effective costs of labor. While natural resources, $T_{j, t}$, and pure TFP, $A_{j, t}$, enhance the amount of human and physical capital a country should receive, the cost in terms of output of both factors, respectively $P_{j, t}^{K} / P_{j, t}^{Y}$ and $P_{j, t}^{C} w_{j, t}^{h} / P_{j, t}^{Y}$, reduces them. It is trivially true that this maximization dominates the one where only capital can be reallocated. The interesting question is how much and whether the capital flows change in magnitude and direction.

\section{THE MARGINAL PRODUCT OF HUMAN CAPITAL}

First, we report salient features of the behavior of the cross-country dispersion in the marginal product of human capital (MPH). These results complement the characterization in the behavior of the marginal product of physical capital (MPK) provided by Monge-Naranjo, Santaeulàlia-Llopis, and Sánchez (2019). The dispersion of MPH is large and growing over time, and the accumulation of human capital does not track the behavior of the determinants of MPH. Second, to the extent that differences in MPH are driven by barriers to the mobility of labor across countries, the global gains of reallocating human capital would be an order of magnitude higher than those of reallocating physical capital. Third, the ability to reallocate workers would not only enhance the gains in global output from reallocating physical capital, but, more interestingly, also induce a reversal in the direction of reallocation of capital across countries. Instead of flowing from richer to poorer countries, capital from poorer countries 


\section{Table 1}

Decomposition of the Variance of $\mathrm{MPH}_{j, t}, \mathbf{1 9 7 0 - 2 0 0 0}$

\begin{tabular}{|c|c|c|c|c|c|c|c|c|}
\hline \multirow[b]{2}{*}{ Year } & \multicolumn{3}{|c|}{ Variances (logs of each variable) } & \multicolumn{5}{|c|}{ Covariances (logs of each variable) } \\
\hline & $\mathrm{QMPH}_{j, t}$ & $\theta_{j, t}$ & $\frac{Y_{j, t}}{H_{j, t}}$ & $\theta_{j, t}, \frac{Y_{j, t}}{H_{j, t}}$ & $Q M P H_{j, t}, Q M P K_{j, t}$ & $Q M P H_{j, t} \frac{P_{j, t}^{Y}}{P_{j, t}^{K}}$ & $Q M P H_{j, t}, \frac{Y_{j, t}}{H_{j, t}}$ & $Q M P H_{j, t}, \frac{Y_{j, t}}{K_{j, t}}$ \\
\hline 1970 & 0.756 & 0.064 & 0.788 & -0.048 & -0.082 & -0.019 & 0.740 & -0.042 \\
\hline 1980 & 0.713 & 0.061 & 0.726 & -0.037 & -0.169 & 0.058 & 0.689 & -0.105 \\
\hline 1990 & 0.748 & 0.058 & 0.642 & 0.024 & -0.149 & 0.111 & 0.666 & -0.107 \\
\hline 2000 & 0.978 & 0.059 & 0.899 & 0.010 & -0.038 & 0.029 & 0.909 & -0.021 \\
\hline
\end{tabular}

SOURCE: Authors' calculations based on PWT 8.0.

would follow some of their workers in the direction of richer countries. This simple result could be useful in understanding the difference between integration agreements with labor mobility (e.g., the European Union) and without it (e.g., the North American Free Trade Agreement [NAFTA]).

We can simply decompose the cross-sectional variance of $\ln Q M P H_{i, j}$ in terms of the labor share of output and the output-to-human capital ratios:

$$
\operatorname{var}\left[\ln Q M P H_{j, t}\right]=\operatorname{var}\left[\ln \theta_{j, t}\right]+\operatorname{var}\left[\ln \left(Y_{j, t} / H_{j, t}\right)\right]+2 \operatorname{cov}\left[\ln \theta_{j, t}, \ln \left(Y_{j, t} / H_{j, t}\right)\right] .
$$

Table 1 reports the values of these variances and the covariances for a number of years in the sample period. The right side of the panel also reports a number of covariances of interest with respect to the joint reallocation of human and physical capital across countries.

There is an upward trend in the dispersion in the $\ln Q M P H$. From a low value of 0.713 in 1980 , the variance in $\ln Q M P H$ grows thereafter until reaching its highest value of 0.978 in 2000. Almost all of the variation is driven by the dispersion in $\ln \left[Y_{j, t} / H_{j, t}\right]$. Indeed, the crosscountry correlation between $\ln Q M P H$ and $\ln \left[Y_{j, t} / H_{j, t}\right]$ is always above 0.95 . Cross-country variation in the labor shares of output, $\ln \theta_{j, t}$, accounts for at most 9 percent of the variation in $\ln Q M P H$ and tends to remain flat, mildly oscillating around 7 percent to 8 percent, during the sample period. The covariance between $\ln \theta_{j, t}$ and $\ln \left[Y_{j, t} / H_{j, t}\right]$ provides a negligible contribution.

The cross-country covariation between the marginal products of human and physical capital is key for the potential gains of jointly reallocating these factors. We find that this covariation is negative, but its magnitude is weak. The same applies to the other factors shown in the last four columns of Table 1. In the next section, we use the simple efficiency benchmarks derived above to assess the potential global gains of reallocating physical and human capital across countries. 


\section{Figure 1}

\section{Global Output Gains of Production Factors Reallocation}

A. Reallocating $\mathrm{H}$ and $\mathrm{K}$

Gains, \% Change in Global Output

80

- - - Equalizing Quantity MPH \& MPK

Equalizing Value MPH \& MPK

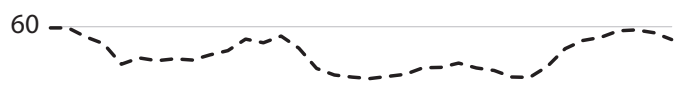

40

20

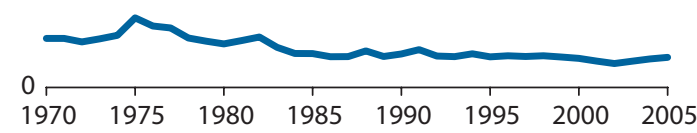

B. Reallocating Only H

Gains, \% Change in Global Output

80

- - - Equalizing Quantity MPH

Equalizing Value MPH

60

40

20

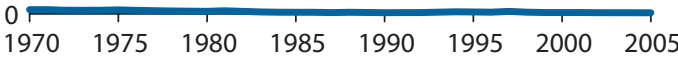

SOURCE: Authors' calculations based on PWT 8.0, World Bank, and the Food and Agriculture Organization of the United Nations (FAOSTAT).

\section{GAINS OF REALLOCATION}

We compute the gains of reallocation for two samples. The first one consist of 76 countries with consistent reliable data for the years 1970 to 2005 . Then, we extend the sample to 107 countries, considering countries with data available for the year 2005.

\subsection{Results for the Years 1970 to 2005}

Figure 1 shows the global output gains of reallocating both physical and human capital (Panel A) and human capital only (Panel B). In each panel, the dashed lines represent the gains from the benchmark. The solid lines represent the gains from the value benchmark defined above.

The most salient result is that the global gains of reallocating workers can be very large. The quantity benchmark indicates that, for all the years in the sample, the global gains would be approximately 40 percent of world output (see Panel B of Figure 1). Those gains remain relatively flat over the sample period. Although reallocating human capital per se leads to very large gains in the quantity benchmark counterfactual, they do not account for the total gains of joint reallocation, since the gains of reallocating both physical and human capital are even larger (see Panel A of Figure 1), in the range of 55-60 percent of global output.

The more restricted value benchmark also indicates large gains, but only when reallocating both human and physical capital. Under this benchmark, almost by construction, the gains of reallocating human capital only would be negligible and mostly driven by a handful of countries with dissimilar output and consumption prices. To be sure, the complementarity 


\section{Figure 2}

\section{Countries' Physical Capital Observed in 2005 and Counterfactual Reallocation}

\section{A. Reallocating Only K, Baseline Benchmark}

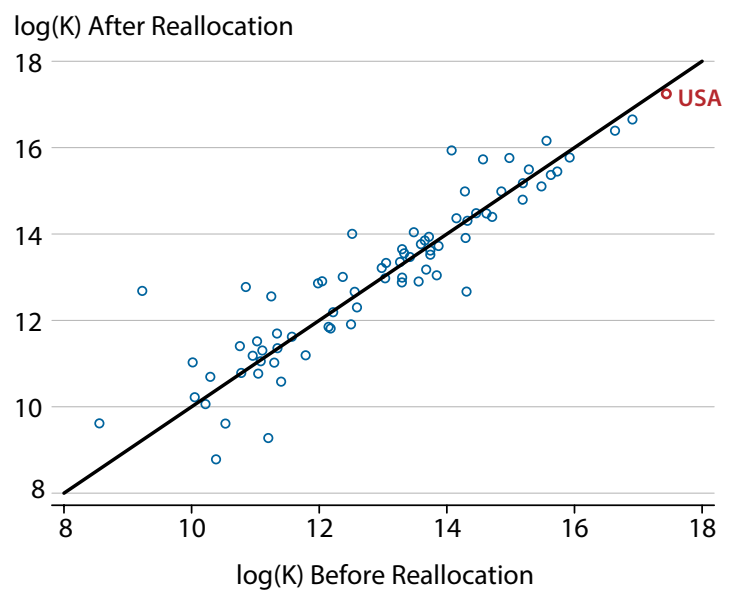

\section{Reallocating Only K, Value Benchmark}

$\log (\mathrm{K})$ After Reallocation

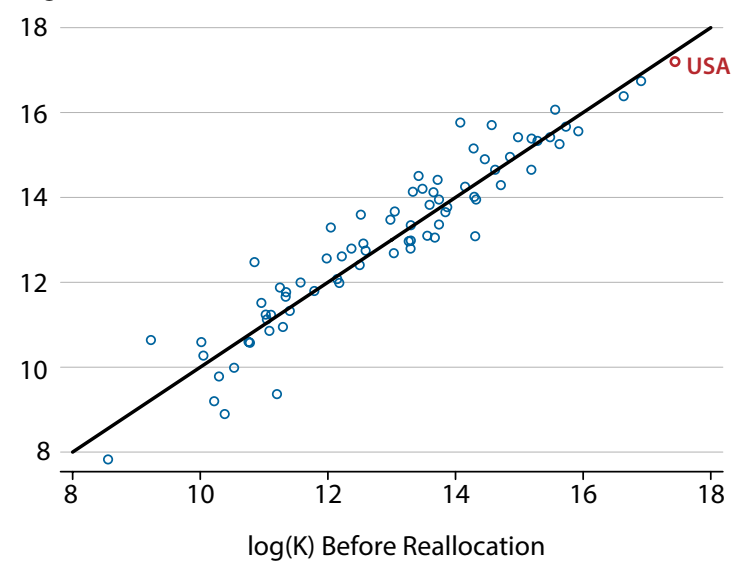

\section{B. Reallocating $\mathrm{K}$ and $\mathrm{H}$, Baseline Benchmark}

$\log (\mathrm{K})$ After Reallocation

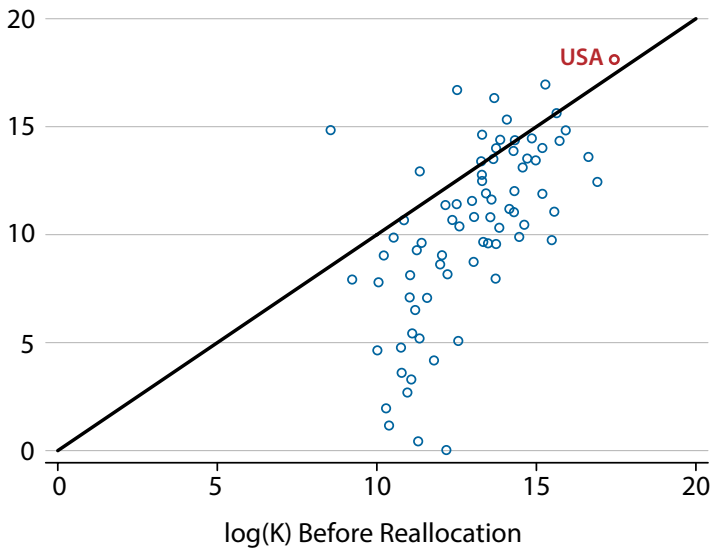

D. Reallocating $\mathrm{K}$ and $\mathrm{H}$, Value Benchmark $\log (\mathrm{K})$ After Reallocation

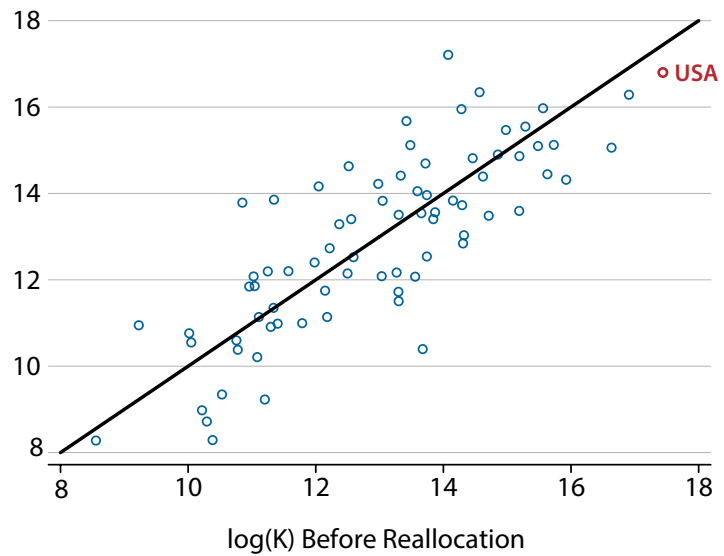

SOURCE: Authors' calculations based on PWT 8.0, World Bank, and the Food and Agriculture Organization of the United Nations (FAOSTAT).

between these two factors is an important determinant for the gains of jointly reallocating physical and human capital.

Most interestingly, under both the baseline and the more restrictive benchmark, we find that jointly reallocating physical and human capital across countries can lead to capital flow reversals relative to reallocating physical capital only. This is not a minor point. In cases in which only physical capital can be reallocated, that physical capital would flow from rich to poor countries, as highlighted by Lucas (1990) long ago and explored further by an extensive 


\section{Figure 3}

\section{Gains of Reallocating Human and Physical Capital Across Income Quartiles}

\section{A. Quantity}

Gains, \% Change in Output

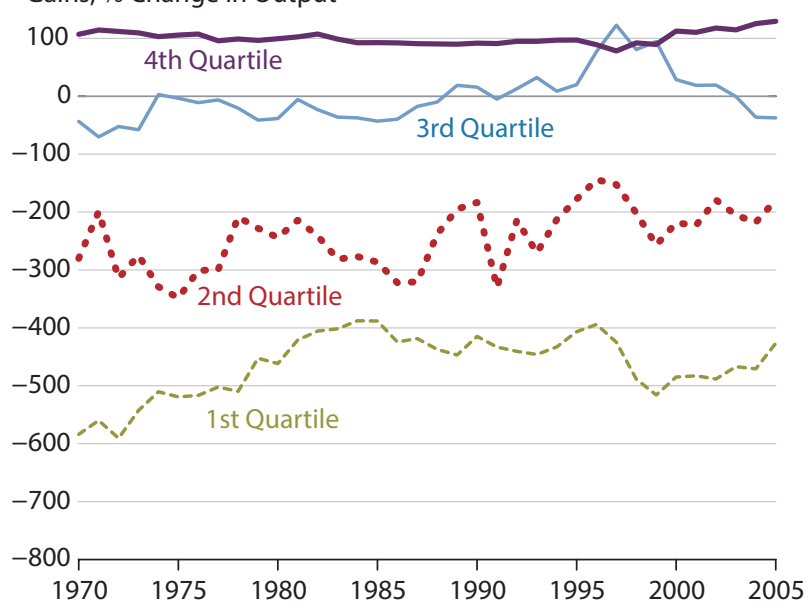

B. Value

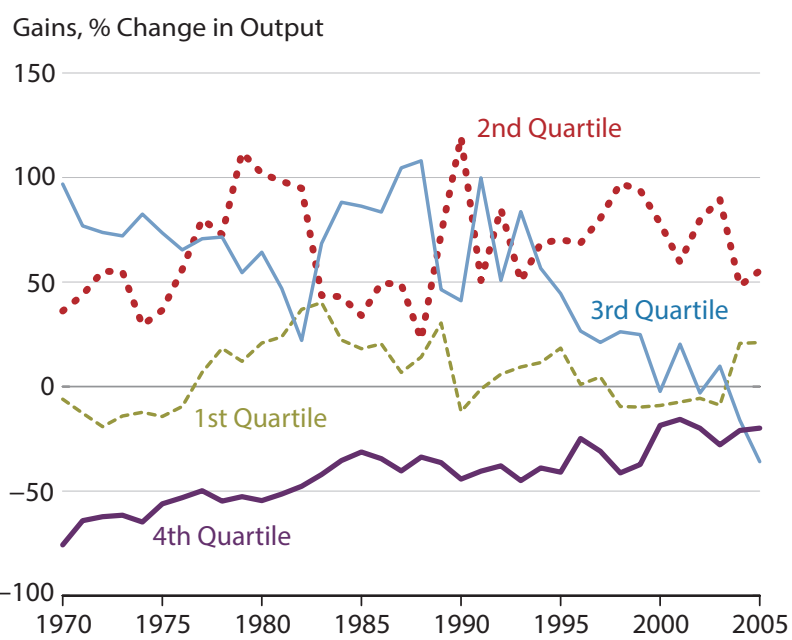

NOTE: Results of equalizing QMPK and QMPH (Panel A) and VMPK and VMPH (Panel B) across countries from 1970 to 2005.

SOURCE: Authors' calculations based on PWT 8.0, World Bank, and FAOSTAT.

ensuing literature. In cases in which both physical capital and human can be reallocated, both may flow toward some of the rich countries, often from poor countries. This simple yet often ignored point could be one of the keys to understanding the consequences of alternative integration schemes with or without labor mobility for countries and regions with different productivities and fixed endowments (e.g., the United States and Puerto Rico and the European Union on one side, with NAFTA on the other).

To illustrate this result, for 2005, the last year in our baseline sample, Figure 2 reproduces the observed physical capital (horizontal axes, in logs) and compares it with the hypothetical level that each country would receive under the different counterfactual exercises (vertical axes, in logs.) In Panels A and B, we compare the results from the baseline, real quantities exercise. In Panels $\mathrm{C}$ and $\mathrm{D}$, we compare the results from the more restrictive value exercise. In the left panels, $A$ and $C$, we report the results for reallocating only physical capital. ${ }^{6}$ In the right panels, $\mathrm{B}$ and $\mathrm{D}$, we report the results for reallocating both physical and human capital.

As anticipated above, Figure 2 shows that the implied reallocation of capital can reverse direction and instead of moving from rich to poor countries, may end up moving from some poor-and some rich-countries to other rich countries. Noticeably, when reallocating only physical capital, the observed levels and the resulting levels are fairly similar; that is, the observations are concentrated near the 45-degree line. This is true regardless of whether we use the baseline or the restricted value benchmark. However, the patterns are very different in the right panels, when reallocating both physical and human capital. In those cases, we see that 
quite a few countries with low levels of physical capital would end up having even lower levels after the efficient reallocations. This is evident especially in Panel B, where many countries lie much lower than the 45-degree line. But notice that it is not only that capital would flow from poor to rich countries, but indeed, there would be massive flows from some rich to other rich countries.

To examine these distributional implications further, in Figure 3 we show the hypothetical change in the output of the countries grouped by income quartiles. ${ }^{?}$ In Panel A, we show the results of equating both quantity marginal products-QMPK and $Q M P H-$ across all countries. Panel B shows the results for the more restricted counterfactual equating VMPK and VMPH across countries, where we impose that the wages of workers across countries must remain constant at the level before the reallocation. Two interesting patterns emerge. First, in the quantity counterfactual, the richer countries (fourth quartile) and sometimes the middle-to-high income countries (third quartile) would expand production, while the poorer countries (first and second quartiles) always contract. Such a reallocation from poor to rich necessarily involves physical capital. Clearly, the required reallocation is exactly the opposite from Lucas (1990). This simple result could prove useful for understanding the resulting capital flows from economic integrations, differentiating between those in which workers can be reallocated (e.g., the European Community and the United States and Puerto Rico) and those in which they cannot (e.g., NAFTA and the Central America-Dominican Republic Free Trade Agreement [CAFTA]). This simple result could also be useful in understanding the allocation of physical and human capital across regions within large countries (e.g., the United States, Brazil, and China).

Second, the quantity and the value counterfactuals lead to very different reallocation patterns. Once we impose the distributional restriction that foreign workers must earn the same income as domestic workers, the direction of global reallocation reverts, from rich to poor countries. Wage restrictions of the form imposed here endogenously make the human capital of countries behave as fixed factors, and reallocations tend to be similar as when physical capital is the only mobile factor. The wages of developed countries are too high, resulting in factor flows to countries in the second and third income quartiles, but not to the poorest ones, because of their lower productivity and larger curvature.

\subsection{Results Extending the Sample of Countries}

So far, we focused on a sample of 76 countries for which we were able to consistently retrieve information on rents of natural resources, factor shares, physical capital, human capital, and output, from 1970 to 2005. With improvement in data collection with time, as well as the emergence of new countries in the 1990s (for example, after the fall of communism in Eastern Europe), data for more countries are available now than in the past. In this section, we extend our benchmark sample to the set of 107 countries for which we can retrieve all necessary information to perform our analysis for the year 2005. Thus, we explore the robustness of our main results to the increased sample size.

In Table 2, we compare the global output gains from equalizing physical and human capital between our benchmark sample and the extended sample. We find minor differences across samples-if at all; our benchmark sample tends to underestimate the global gains of 


\section{Figure 4}

\section{Winners and Losers of Reallocation with the Extended Sample: Output Gains (\%) from Equalizing QMPH}

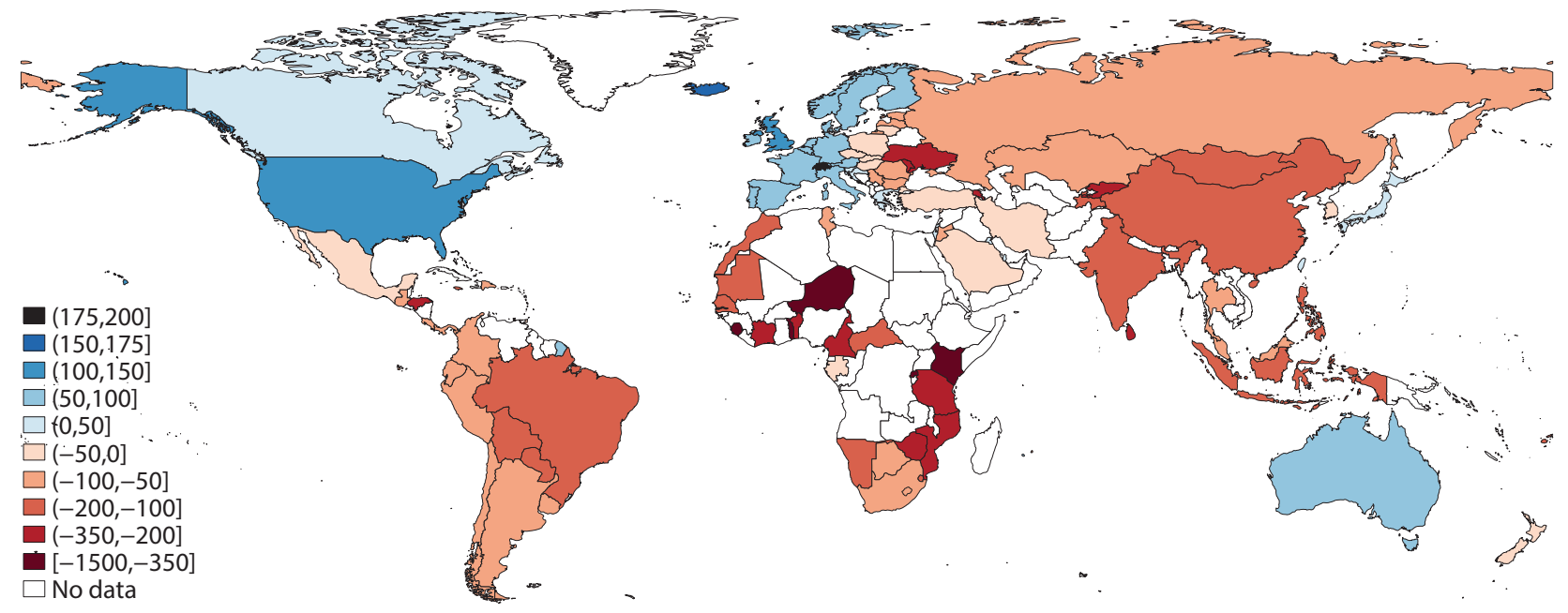

SOURCE: Authors' calculations based on PWT 8.0, World Bank, and FAOSTAT.

Table 2

Comparing Gains in Output, 2005

\begin{tabular}{lccccc} 
& \multicolumn{2}{c}{ Quantity (\%) } & & \multicolumn{2}{c}{ Value (\%) } \\
\cline { 2 - 3 } \cline { 5 - 6 } & Benchmark & Extended sample & & Benchmark & Extended sample \\
\hline Equalizing MPH & 42.52 & 42.18 & & 0.25 & 0.25 \\
\hline Equalizing MPK \& MPH & 55.96 & 57.32 & & 5.78 & 7.74 \\
\hline Number of countries & 76 & 107 & 76 & 107 \\
\hline
\end{tabular}

SOURCE: Authors' calculations based on PWT 8.0, World Bank, and FAOSTAT.

reallocation compared with the extended sample. First, equalizing MPH yields similar insights. Second, the joint global reallocation of physical and human capital implies that, in quantity terms, our output gains in the benchmark sample are 55.96 percent, while in the extended sample they are 57.32 percent. That is, our extended sample leads to more global output gains. These underestimations are more apparent in value terms, where the output gains are 5.78 percent in our benchmark sample and 7.74 percent in our extended sample.

For the extended sample, in Figure 4 we use maps to show winners and losers of reallocation. The pattern of reallocation of human capital is quite interesting. The countries receiving migrants (blue in the map) are all developed: the United States, Canada, Western Europe, and Australia. The countries sending the most human capital abroad are China, India, Ukraine, Brazil, and other Eastern European and African countries. 


\section{Table 3}

Population-Weighted OLS Regression, $\Delta H, 1970-2005$

\begin{tabular}{|c|c|c|c|c|c|c|}
\hline & (1) & (2) & (3) & (4) & (5) & (6) \\
\hline$\Delta \ln Z$ & $0.081(0.085)$ & $0.098(0.091)$ & $0.044(0.093)$ & $-0.044(0.095)$ & $-0.021(0.089)$ & $-0.067(0.083)$ \\
\hline$\Delta \ln K$ & $0.092(0.069)$ & $0.033(0.070)$ & $0.070(0.106)$ & $0.117^{*}(0.067)$ & $0.065(0.062)$ & $0.109(0.081)$ \\
\hline$\Delta \ln \theta$ & $-1.133^{* *}(0.429)$ & $-0.935^{* *}(0.385)$ & - & $-0.706(0.429)$ & $-0.568(0.383)$ & - \\
\hline$\Delta \ln \frac{P_{Y}}{P_{C}}$ & $1.157^{* *}(0.455)$ & - & - & $1.083^{* * *}(0.373)$ & - & - \\
\hline$V M P H_{1970} \times 10^{-3}$ & $-0.015(0.014)$ & - & - & $-0.025(0.015)$ & - & - \\
\hline$Q M P H_{1970} \times 10^{-3}$ & - & $-0.024 *(0.014)$ & - & - & $-0.030(0.018)$ & - \\
\hline$\left(\frac{Y}{H}\right)_{1970} \times 10^{-3}$ & - & - & $-0.014(0.013)$ & - & - & $-0.011(0.013)$ \\
\hline $\begin{array}{l}\text { Includes OECD } \\
\text { countries }\end{array}$ & $\mathrm{Y}$ & Y & Y & $\mathrm{N}$ & $\mathrm{N}$ & $\mathrm{N}$ \\
\hline Observations & 76 & 76 & 76 & 53 & 53 & 53 \\
\hline$R^{2}$ & 0.411 & 0.340 & 0.176 & 0.471 & 0.349 & 0.174 \\
\hline $\begin{array}{l}\text { NOTE: OECD, Organi } \\
*^{* * *} p<0.01 . \\
\text { SOURCE: Authors' ca }\end{array}$ & $\begin{array}{l}\text { sation for Economic } \\
\text { Iculations based on }\end{array}$ & $\begin{array}{l}\text { Co-operation and De } \\
\text { WT 8.0, World Bank, }\end{array}$ & $\begin{array}{l}\text { opment. Robust } \\
\text { d FAOSTAT. }\end{array}$ & dard errors are in & ntheses. ${ }^{*} p<0$ & ${ }^{*} p<0.05$, and \\
\hline
\end{tabular}

\section{ANOTHER REALLOCATION PUZZLE?}

The previous results suggest that instead of physical capital, the culprit of misallocation is human capital. Even in our restrictive value benchmark, the ability to reallocate workers across countries would greatly enhance the global output gains of reallocating physical capital. Moreover, there is indication that the allocation of labor has not improved over time, because the gains of joint reallocation are flat over time, while the gains of reallocating physical capital have declined-as shown by Monge-Naranjo, Santaeulàlia-Llopis, and Sánchez (2019). There is already a literature discussing the puzzling direction of physical capital flows (Feldstein and Horioka, 1980; Gourinchas and Jeanne, 2013; Ohanian, Restrepo-Echavarria, and Wright, 2013; and Monge-Naranjo, Santaeulàlia-Llopis, and Sánchez, 2019). In this section, we conduct an analogous analysis of human capital flows.

To examine whether there is a reallocation puzzle for human capital, we regress the change in human capital on several variables and find the following: The measure of initial MPH appears insignificant in accounting for the change in human capital (displayed in Table 3). Changes in TFP and physical capital are insignificant in accounting for changes in human capital. The R-squared values of these regressions are low, indicating that these forces are not that important in driving investment in human capital. These results seem to be in line with Easterly (2001, pp. 72-73), who argues that "The growth response to the dramatic educational 


\section{Figure 5}

\section{Counterfactual Global Output Gains of Production Factors Reallocation}
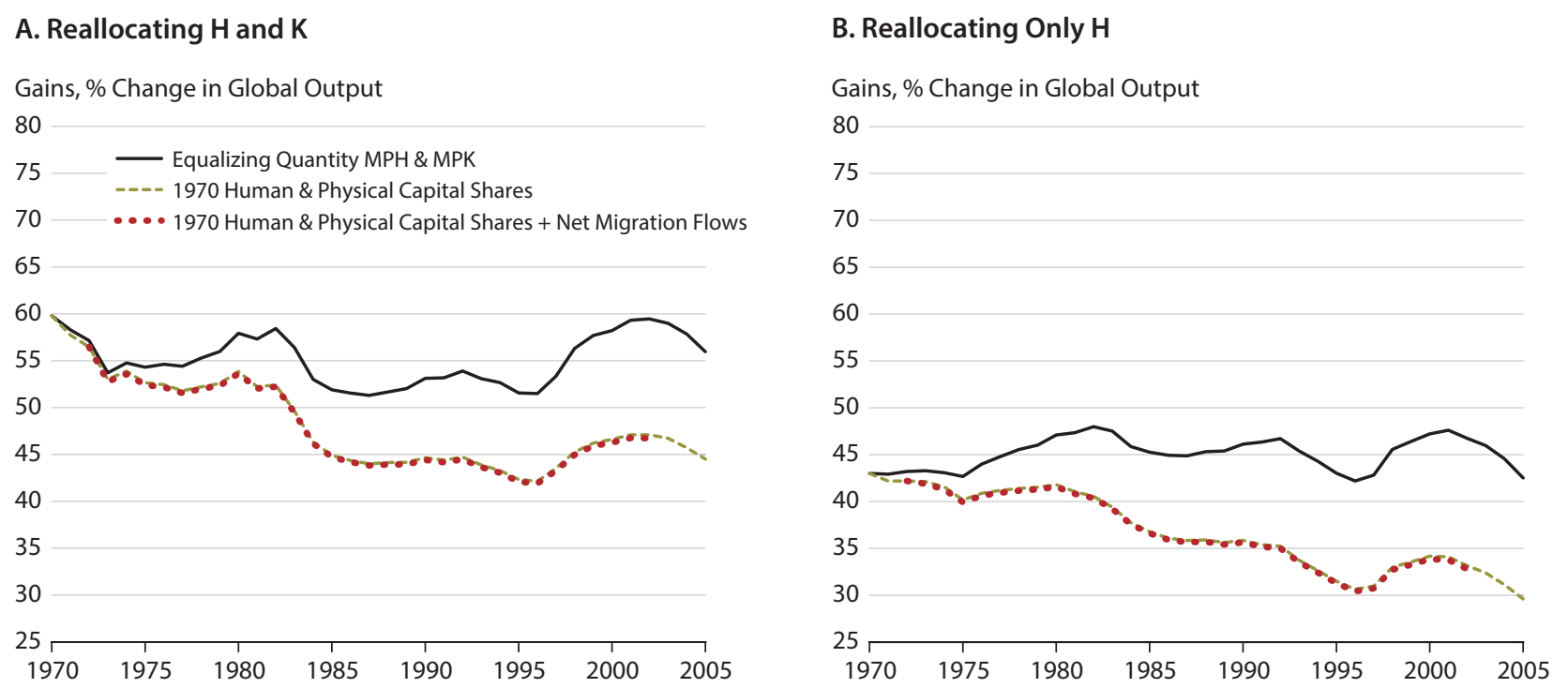

SOURCE: Authors' calculations based on PWT 8.0, World Bank, and FAOSTAT.

expansion of the last four decades has been distinctly disappointing...creating skills where there exists no technology to use them is not going to foster economic growth."

To measure the role of human capital flows more directly, we construct a counterfactual sequence of human capital stock for each country $\tilde{H}_{j, t}$. More precisely, the stock of human capital of country $j$ in year $t$ is

$$
\tilde{H}_{j, t}=s_{j, 1970} \cdot H_{W, t},
$$

where $H_{W, t}$ is the world stock of human capital and $s_{j, 1970}=\frac{H_{j, 1970}}{H_{W, 1970}}$.

We also examine the flows of human capital by analyzing net migration flows to each particular country $\left\{f_{j, t}^{H}\right\}$. Since we do not have information about the human capital of the migrants, we assume that migration changes the number of persons living in a country but not the average human capital index or the share of people employed. For example, that would be the case if the net flows from each country have the same characteristics as the population of that country.

Data on net migration are taken from the World Bank and are available at 5-year intervals starting in 1972; we use linear interpolation to infer missing flows. To construct human capital flows $\hat{f}_{j, t}^{H}$ from population flow data $f_{j, t}^{H}$, we make several assumptions. We assume that a share $d_{t}$ of migrants $f_{j, t}^{H}$ are employees. This share is equal to the average employment-to-population ratio: 


$$
d_{t}=\sum_{j}^{N} \frac{L_{j, t}}{P_{j, t}} / N
$$

To convert these employment flows $d_{t} f_{j, t}^{H}$ to human capital-augmented labor $\hat{f}_{j, t}^{H}$, we assume that migrant human capital is equal to the human capital in the country $h_{j, t}$ into/out of which labor is flowing, so that $\hat{f}_{j, t}^{H}=h_{j, t} \cdot\left(d_{t} f_{j, t}^{H}\right)$. Assuming migrant human capital is equal to the global mean yields similar results. As with physical capital, the sum of human capital flows does not add to zero. Adjusting the flows to ensure these flows add to zero does not change our results.

We find that the observed investments in human capital since 1970 made the global allocation of human capital significantly worse (Figure 5). If in 2005 human capital had been distributed according to the shares per country in 1970, the gains of reallocation would have been 30 percent instead of 43 percent. The difference, 13 percent of global output, is a measure of how much worse the allocation of human capital is due to changes that have taken place since 1970. Adding migration flows does not change the picture, so the changes in human capital that worsen the allocation of human capital are internal.

\section{CONCLUSIONS}

We use new data on natural resources shares from Monge-Naranjo, Santaeulàlia-Llopis, and Sánchez (2019) to uncover the degree of global misallocation of human capital. We find the implied global efficiency losses of the misallocation of human capital are almost 60 percent. If anything, the misallocation of human capital seems to have worsened. Some interesting patterns arise when we explore the joint reallocation of physical and human capital. First, the gains are substantially higher. Second, the direction of reallocation can change and, instead of capital flowing from rich to poor countries, as first explored by Lucas (1990), we find that capital - and workers — should flow from poor to rich countries. This simple point could help in understanding the consequences of alternative integration schemes with or without labor mobility for countries and regions with different productivities and fixed endowments (e.g., the United States and Puerto Rico and the European Community on one side, with NAFTA on the other). 


\section{Monge-Naranjo, Sánchez, Santaeulàlia-Llopis, Sohail}

\section{NOTES}

1 According to the Monge-Naranjo, Santaeulália-Llopis, and Sánchez (2019) estimate, the gains of just reallocating physical capital for the same countries and years are about 3 percent.

2 We focus on the human capital measure available in PWT 8.0 since our exercise requires a measure that is widely available for many countries, including those at the bottom of the income distribution. Models with imperfect substitutability (e.g., Jones, 2014, and Caselli and Ciccone, 2019) and comparative advantage (e.g., Hsieh et al., forthcoming, and Monge-Naranjo, Mies, and Tapia, 2019) would provide a richer framework to evaluate the gains of reallocating different types of workers across countries but would require much more data and/or estimates across many countries.

3 See Cooley and Prescott (1995), Gollin (2002), and Feenstra, Inklaar, and Timmer (2015).

4 Modeling and empirically disciplining the workers' compensating differences for living and working in different countries lies outside the limits of this article. See Klein and Ventura (2009) for interesting quantitative work.

$\underline{5}$ See the discussion in Section 1 of Monge-Naranjo, Santaeulàlia-Llopis, and Sánchez (2019.)

6 See Monge-Naranjo, Santaeulàlia-Llopis, and Sánchez (2019) for a more detailed discussion of the reallocation of capital.

$\underline{7}$ These are simple quartiles, that is, unweighted by population or other criteria for size.

\section{REFERENCES}

Caselli, F. and Feyrer, J. “The Marginal Product of Capital." Quarterly Journal of Economics, 2007, 122(5), pp. 535-68; https://doi.org/10.1162/qjec.122.2.535.

Caselli, F. and Ciccone, A. "The Human Capital Stock: A Generalized Approach: Comment." American Economic Review, March 2019, 109(3), pp. 1155-74; https://doi.org/10.1257/aer.20171787.

Cooley, T.F. and Prescott, E.C. "Economic Growth and Business Cycles," in T. F. Cooley, ed., Frontiers of Business Cycle Research. Princeton University Press, 1995, pp. 1-38.

Easterly, W. The Elusive Quest for Growth: Economists'Adventures and Misadventures in the Tropics. MIT Press, 2001.

Feenstra, R.C.; Inklaar, R. and Timmer, M. "The Next Generation of the Penn World Table." American Economic Review, October 2015, 105(10), pp. 3150-83; https://doi.org/10.1257/aer.20130954.

Feldstein, M. and Horioka, C. "Domestic Saving and International Capital Flows." Economic Journal, June 1980, 90, pp. 314-29; https://doi.org/10.2307/2231790.

Gollin, D. "Getting Income Shares Right." Journal of Political Economy, April 2002, 110, pp. 458-74; https://doi.org/10.1086/338747.

Gourinchas, P.-O. and Jeanne, O. "Capital Flows to Developing Countries: The Allocation Puzzle." Review of Economic Studies, October 2013, 80(4), pp. 1484-515; https://doi.org/10.1093/restud/rdt004.

Hsieh, C.-T.; Hurst, E.; Jones, C. and Klenow, P. "The Allocation of Talent and U.S. Economic Growth." Forthcoming in Econometrica.

Jones, B.F. "The Human Capital Stock: A Generalized Approach." American Economic Review, 2014, 104, pp. 3752-777; https://doi.org/10.1257/aer.104.11.3752.

Kennan, J. “Open Borders." Review of Economic Dynamics, April 2013, 16, pp. L1-L13; https://doi.org/10.1016/j.red.2012.08.003.

Klein, P. and G. Ventura. "Productivity Differences and the Dynamic Effects of Labor Movements." Journal of Monetary Economics, November 2009, 56, pp. 1059-73; https://doi.org/10.1016/j.jmoneco.2009.10.011.

Lucas, R.E. "Why Doesn't Capital Flow from Rich to Poor Countries?" American Economic Review, May 1990, 80, pp. 92-96. 
Monge-Naranjo, Sánchez, Santaeulàlia-Llopis, Sohail

Monge-Naranjo, A.; Santaeulàlia-Llopis, R. and Sánchez, J.M. "Natural Resources and Global Misallocation." American Economic Journal: Macroeconomics, April 2019, 11(2), pp. 79-126; https://doi.org/10.1257/mac.20170381.

Monge-Naranjo, M.; Mies, V.A. and Tapia, M. "On the Assignment of Workers to Occupations and the Human Capital of Countries." Working paper, 2019.

Ohanian, L.E.; Restrepo-Echavarria, P. and Wright, M.L.J. "Bad Investments and Missed Opportunities? Capital Flows to Asia and Latin America, 1950-2007." Working Paper No. 2014-38, Federal Reserve Bank of St. Louis, November 2013; https://doi.org/10.20955/wp.2014.038. 
